\title{
Self-Compacting Concrete Properties of Recycled Coarse Aggregate
}

\author{
R. Premkumar ${ }^{1, a^{*}}$, Ramesh Babu Chokkalingam ${ }^{1}$, Vemula Jayanth Kumar ${ }^{1}$ \\ ${ }^{1}$ School of Environmental and Construction Technology, Department of Civil Engineering, \\ Kalasalingam Academy of Research and Education, Krishnankoil, Tamil Nadu, India. \\ aprem.ce@gmail.com \\ * Corresponding author
}

\begin{abstract}
Keywords: Self-Compacting Concrete, Recycled Coarse Aggregate, Mechanical, Durability
\end{abstract}

\begin{abstract}
Self-compacting concrete, which is characterized by its capacity to flow, can also consolidate under its weight. Hardened concrete from concrete building demolition can be used to partially replace natural coarse aggregate in self-compacting concrete. The current study compares the properties of self-compacting concrete with 0 percent, $25 \%, 50 \%, 75 \%$, and $100 \%$ substitution of recycled coarse aggregate in the fresh and hardened states. The evolution of passing ability properties using the L-box test, filling ability properties using the slump cone test, and segregation properties using the $\mathrm{V}$-funnel test are also included. Compression, tension, and flexural strength are all checked for hardened properties. Rapid chloride permeability and sorptivity tests are used to assess durability. The experimental program revealed that at RCA utilization levels of $25 \%$ to $50 \%$, little to no negative impact on power, workability, or durability properties was observed.
\end{abstract}

\section{Introduction}

The use of sustainable materials has become increasingly common in recent years. By that the use of nonrenewable natural resources, sustainability benefits the ecosystem. Concrete, the world's second most used commodity after water, consumes a large amount of non-renewable energy. As a result, several studies have looked into the use of recycled materials in the manufacturing process. The use of sustainable materials has become increasingly common in recent years [1]. By that the use of nonrenewable natural resources, sustainability benefits the ecosystem. Concrete, the world's second most used commodity after water, consumes a large amount of non-renewable energy. Accordingly, a few investigations have investigated the utilization of reused materials in the assembling interaction [2]. The utilization of reused totals in the creation of new cement seems to have a great deal of guarantee. It considers the goal of issues identified with the assortment, transportation, and removal of building and destruction squander, just as adding to a conceivably more feasible environment through an improvement in the estimation of such squanders, accordingly lessening the utilization of common aggregate [3]. The examination of self-compacting concrete (SCC) with RA, yet then again, should prompt a compelling assessment between the R\&D zones and the genuine requirements from both the development business and its last customers because the capacity to customer needs and the relationship execution quality-cost is the key distinctive components of sound rivalry in the development business. It can be difficult to ensure that the formwork is properly stacked, that is, completely compacted without voids or honeycombs, when a large amount of generous assistance is to be put in a shaped cement (RC) section. 
Compaction with a manual or electronic vibrator is extremely difficult in this case. Underwater concreting necessitated the use of fresh concrete that could be installed without the need for compaction; vibration was simply not an option in such circumstances [4]. This problem can now be solved with self-compacting concrete. This research will look at the long-term properties of SCC with recycled coarse and fine aggregates, as a follow-up to a previous study that looked at the long-term behaviour of structural concrete with coarse and fine aggregates [5]. Accordingly, the impacts of different plans on SCC properties in both new and solidified states are examined to evaluate the practicality of SCC with incredible mechanical obstruction [6]. As a result, when compared to standard aggregate concrete, RAC structural components typically have poor mechanical and physical properties, such as weak mechanical low productivity, and poor durability behavior [7]. RAC concrete made entirely of recycled aggregates was said to have a lower compressive strength [8]. Previous research studies have shown that some of the disadvantages of recycled aggregate concrete include greater drying shrinkage and creep, as well as chemical resistance to chloride-ion penetration when compared to standard concrete. However, this weakness can be mitigated by applying a small amount of fly ash to the concrete mix, as fly ash is known to minimize drying shrinkage, creep, and chloride ion penetration in concrete [9]. This study aims to fill a significant gap in the current literature by investigating the versatile properties of SCCs with characteristic coarse total subbed with RCA at levels of $0 \%$ (control), $25 \%$, half, $75 \%$, and $100 \%$. To better understand the impact of RCA on these properties, SCC intensity characteristics are analyzed at each of the RCA utilization stages.

\section{Materials}

Ordinary Portland cement (Grade 53) conforming to IS12269:1987 was used in all of the formulations. After 28 days, it weighed 3.23 specific gravity, $380 \mathrm{~m}^{2} / \mathrm{kg}$ specific surface area, and $58 \mathrm{MPa}$ compressive pressures. To increase the powder content in SCC, Elkem Company's grade $920 \mathrm{D}$ silica fume with a specific gravity of 2.3 was used. As the natural aggregate, crushed basalt with a maximum size of $10 \mathrm{~mm}$ was collected from a nearby stone quarry. Crushed concrete rubbles from building demolition campaigns made up almost all of the recycled aggregate. Demolished concrete aggregates were crushed in a laboratory jaw crusher to produce a cumulative grain size distribution curve that looked close to that of natural coarse aggregates. The aggregates used were crushed granite with a nominal maximum size of $10 \mathrm{~mm}$ and properties described in table 2. The fine aggregate in the concrete mixtures was river sand.

\section{Mix Proportion}

Five different concrete mixtures were created for the experiment. The following proportions of recycled coarse aggregate were used to replace natural coarse aggregate in each mixture: $0 \%, 25 \%$, $50 \%, 75 \%$, and $100 \%$ by volume. Table 2 shows the specifics of the blended template for each of these five blends. Following the initial mix design, EFNARC guidelines were followed to prepare and test the trial mixes for SCC fresh properties. Because of slightly higher water absorption and minor variations in the amount of superplasticizer used to achieve comparable quality for all blends, the number of components used to manufacture $1 \mathrm{~m} 3$ of concrete remained constant. The specimens were then put in the curing tank to cure after they were de-moulded. In this analysis, compression, flexure, and split tensile strength measuring mechanical properties were cast and stored for 28 days before being tested for strength. The effects of different recycled aggregate concrete on the solidity of SCC were measured using toughness properties including water sorptivity and chloride particle penetration of recycled aggregate concrete above SCC and compared to standard aggregate concrete. 
Table 1..Properties of Aggregate

\begin{tabular}{clll}
\hline S.No & \multicolumn{1}{c}{ Property } & Natural Aggregate & Recycle Aggregate \\
\hline 1 & Specific Gravity & 2.657 & 2.469 \\
2 & Water Absorption & $0.311 \%$ & $2.24 \%$ \\
3 & Fineness Modulus & 6.25 & 5.45 \\
4 & Bulk Density & $1.404 \mathrm{~kg} / 1$ & $1.31 \mathrm{~kg} / 1$ \\
5 & Crushing Value & $28 \%$ & $28 \%$ \\
6 & Impact Value & $21 \%$ & $30 \%$ \\
\hline
\end{tabular}

Table 2.Mix Proportion

\begin{tabular}{|c|c|c|c|c|c|c|c|c|c|c|}
\hline Mix code & $\begin{array}{l}\text { w/b } \\
\text { ratio }\end{array}$ & $\begin{array}{c}\text { Water } \\
\left(\mathrm{kg} / \mathrm{m}^{3}\right)\end{array}$ & $\begin{array}{c}\text { Cemen } \\
\mathbf{t} \\
\left(\mathrm{kg} / \mathrm{m}^{3}\right)\end{array}$ & $\begin{array}{c}\text { Fly } \\
\operatorname{ash}(\mathbf{k g} / \\
\left.\mathbf{m}^{3}\right)\end{array}$ & $\begin{array}{c}\text { Silica } \\
\text { Fume } \\
(\mathbf{k g} / \\
\left.\mathbf{m}^{3}\right)\end{array}$ & $\begin{array}{c}10 \mathrm{~mm} \\
\text { aggregat } \\
\text { e }\left(\mathrm{kg} / \mathrm{m}^{3}\right)\end{array}$ & $\begin{array}{c}\text { Quarry } \\
\text { dust } \\
\left(\mathbf{k g} / \mathbf{m}^{3}\right)\end{array}$ & $\begin{array}{l}\text { Recycl } \\
\text { ed } \\
10 \mathrm{~mm} \\
\left(\mathrm{~kg} / \mathrm{m}^{3}\right)\end{array}$ & $\begin{array}{l}(\%) \text { of } \\
\text { RCA }\end{array}$ & $\begin{array}{c}\text { SP } \\
\left(1 / \mathbf{m}^{3}\right. \\
)\end{array}$ \\
\hline $\mathrm{RC} 0$ & 0.35 & 220 & 450 & 150 & 30 & 650 & 825 & 0 & 0 & 4.5 \\
\hline $\mathrm{RC} 25$ & 0.35 & 220 & 450 & 150 & 30 & 488 & 825 & 162 & 25 & 4.5 \\
\hline RC50 & 0.35 & 220 & 450 & 150 & 30 & 325 & 825 & 325 & 50 & 4.5 \\
\hline RC75 & 0.35 & 220 & 450 & 150 & 30 & 162 & 825 & 488 & 75 & 4.5 \\
\hline $\mathrm{RC} 100$ & 0.35 & 220 & 450 & 150 & 30 & 0 & 825 & 650 & 100 & 4.5 \\
\hline
\end{tabular}

\section{Results and Discussion}

Table 3 shows the droop stream, hindering proportion, and sifter isolation test results for the control SCC and SCCs with various degrees of RCA use. This finding shows that all SCCs have similar flow ability, but that increasing RCA content increases viscosity. Slump flow experiments performed one hour after concrete mixing revealed a similar trend. The t500 times, on the other hand, increased by a greater percentage as the RCA content increased; for example, when moving from control to $100 \%$ RCA, the 5500 times increased by 45 percent at initial measurement and 92 percent after 1 hour (see Table 3). The obvious thickness with developing RCA substance could be because of the RCA's rakish structure, while the time-subordinate move in droop stream results could be because of the reused aggregate proceeded with water ingestion despite being presoaked and dried for one hour before utilizing. Table 3 shows the consequences of the L-box assessment. As referenced in the past section, this test evaluates the SCC's reasonableness for use in a part with blocked support by estimating its passing capacity. In the L-box test one hour after blending, the divergence between the control SCC and the SCCs comprising 75 percent RCA and 100 percent RCA increments. In this study, the obstructing proportions of the 75 percent and 100 percent RCA SCCs were reduced by around $8 \%$ and $10 \%$, respectively, as compared to the normal SCC. Table 3 shows that as the RCA content of the SCCs increased, so did the SCCs' isolation obstruction. This is probably because of the reused aggregate's higher water ingestion capacity. As indicated by each SCC mix falling into the strainer isolation opposition class SR2 (isolation part $<=15 \%$ ), the entirety of the SCCs were considered adequate. 
Table 3. Fresh Concrete Properties

\begin{tabular}{|c|c|c|c|c|c|c|c|c|c|c|}
\hline \multirow{3}{*}{$\begin{array}{l}\text { Mix } \\
\text { code }\end{array}$} & \multirow{3}{*}{$\begin{array}{c}\text { Wet } \\
\text { density } \\
(\mathrm{kg} / \mathrm{m} 3)\end{array}$} & \multicolumn{5}{|c|}{ Slump flow test } & \multicolumn{3}{|c|}{ L-box } & \multirow{3}{*}{$\begin{array}{c}\text { Sieve } \\
\text { segregation } \\
P(\%)\end{array}$} \\
\hline & & \multicolumn{2}{|c|}{ Initial } & \multicolumn{2}{|c|}{ After 1 hr } & \multirow{2}{*}{$\begin{array}{c}\text { Variation } \\
(S 0-S 1 \\
\mathrm{hr}) / S 0(\%)\end{array}$} & \multirow{2}{*}{$\begin{array}{c}\text { Initial } \\
B 0 \\
\text { (ratio) } \\
\end{array}$} & \multirow{2}{*}{$\begin{array}{c}\text { After } 1 \\
\mathbf{h r} \\
B 1 \mathrm{hr} \\
\text { (ratio) }\end{array}$} & \multirow{2}{*}{$\begin{array}{c}\text { Variation } \\
(B 0-B 1 \\
\mathrm{hr}) / B 0(\%)\end{array}$} & \\
\hline & & $\begin{array}{c}S 0 \\
(\mathrm{~mm})\end{array}$ & $\begin{array}{c}\text { T500 } \\
\text { (s) }\end{array}$ & $\begin{array}{c}S 1 \\
(\mathrm{~mm})\end{array}$ & $\begin{array}{c}\text { T500 } \\
(\mathrm{s}) \\
\end{array}$ & & & & & \\
\hline $\mathrm{RC} 0$ & 2375 & 710 & 2.9 & 640 & 3.9 & 9.86 & 0.94 & 0.89 & 5.32 & 9.90 \\
\hline $\mathrm{RC} 25$ & 2360 & 700 & 3.7 & 610 & 5.9 & 12.86 & 0.95 & 0.88 & 7.37 & 7.70 \\
\hline RC50 & 2345 & 720 & 3.9 & 640 & 6.4 & 11.11 & 0.97 & 0.89 & 8.25 & 6.30 \\
\hline RC75 & 2332 & 710 & 4.1 & 610 & 6.9 & 14.08 & 0.92 & 0.82 & 10.87 & 6.00 \\
\hline $\mathrm{RC} 100$ & 2325 & 700 & 4.3 & 580 & 7.6 & 17.14 & 0.93 & 0.80 & 13.98 & 5.20 \\
\hline
\end{tabular}

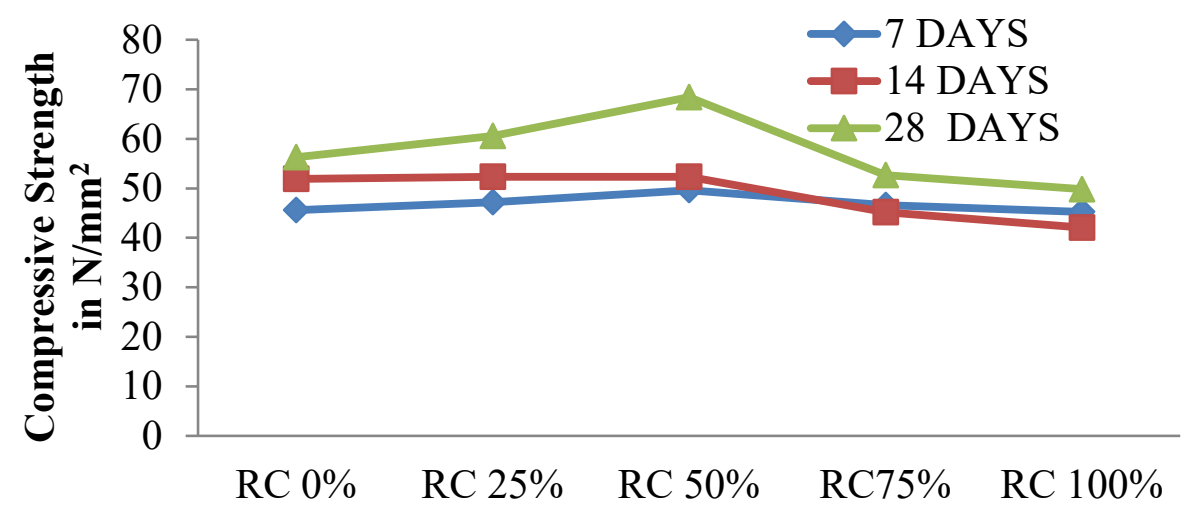

Figure 1.Compressive Strength

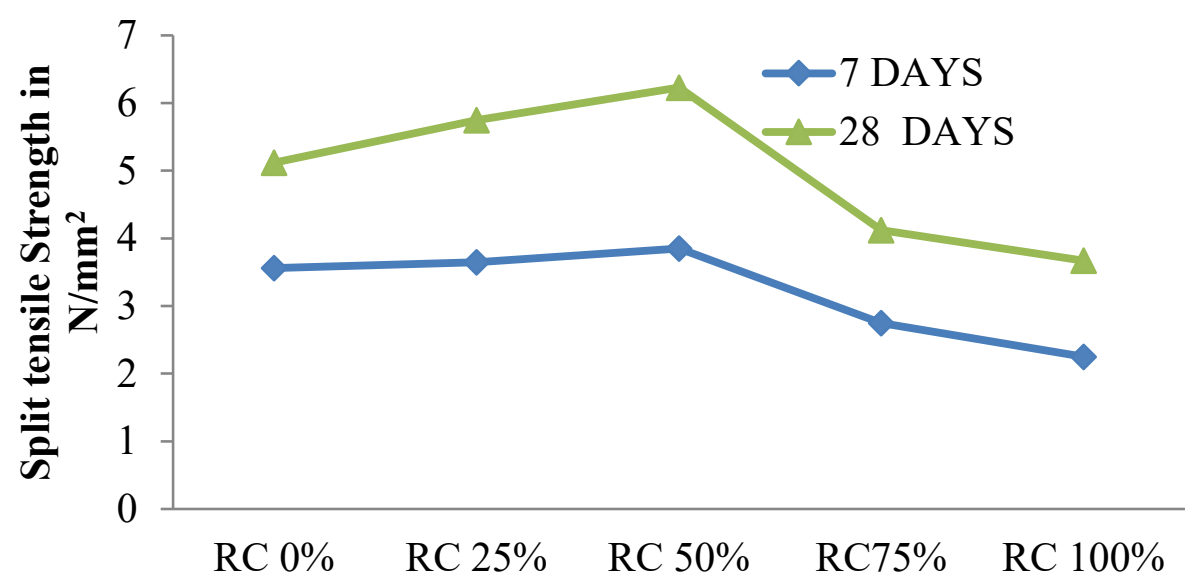

Figure 2.Split tensile strength 


\section{Compressive Strength}

As demonstrated in Figure 1, the compressive strength of 7, 14, and 28 days was a particular rate replacement of coarse total in SCC. The normal strength in three $150 \mathrm{~mm} \times 150 \mathrm{~mm} \times 150 \mathrm{~mm}$ solid shape examples of each blend extent was utilized to acquire the entirety of the test outcomes. RCA0 percent had a compressive strength of $56 \mathrm{~N} / \mathrm{mm}^{2}$ after 28 days; RCA25 percent, 50 percent, 75 percent, and 100 percent concrete mixes with recycling aggregate had compressive strengths of $60 \mathrm{~N} / \mathrm{mm}^{2}, 68 \mathrm{~N} / \mathrm{mm}^{2}, 52 \mathrm{~N} / \mathrm{mm}^{2}$, and $49 \mathrm{~N} / \mathrm{mm}^{2}$, respectively. When taking a gander at the compressive strength of examples, it was discovered that as the level of reuse coarse aggregate replacement was expanded, the compressive strength of the examples diminished after half substitution. In any case, since silica fume was accustomed to restricting substance, the compressive strength was additionally diminished. Aside from RCA25\% and RCA50\% reuse total superseded concrete, the compressive strength of a wide range of cement blends was discovered to be more noteworthy than the plan estimation of solidarity.

\section{Split Tensile Strength}

The ASTM norm was used to calculate the splitting tensile strength of each concrete sequence. As suggested by the ASTM standard, the stacking was applied at a consistent pace of $0.7-1.4 \mathrm{MPa}$ each moment. At a concrete age of 28 days, three $150 \times 300 \mathrm{~mm}$ cylinders were checked for each combination. After a 50 percent replacement mix proportion, raising the amount of recycled aggregate in the concrete mix reduces the concrete's fracturing tensile strength. Silica fume is commonly used to improve the pozzolanic action of SCC concrete. As a result, we've been able to boost all of concrete's mechanical properties. However, applying mineral admixtures to recycled aggregate concrete does not improve its mechanical properties, according to this report. Ordinary concrete has an elasticity of $8-14 \%$ of its compressive power, according to the split tensile measure.

As demonstrated in Figure 3, the level of rigidity comparative with the compressive strength of the relating reuse aggregate cement went from 8-14 percent to 50 percent coarse aggregate substitutions. After more than half of the aggregate was reused, the compressive strength was reduced to less than $8 \%$ of its original value.

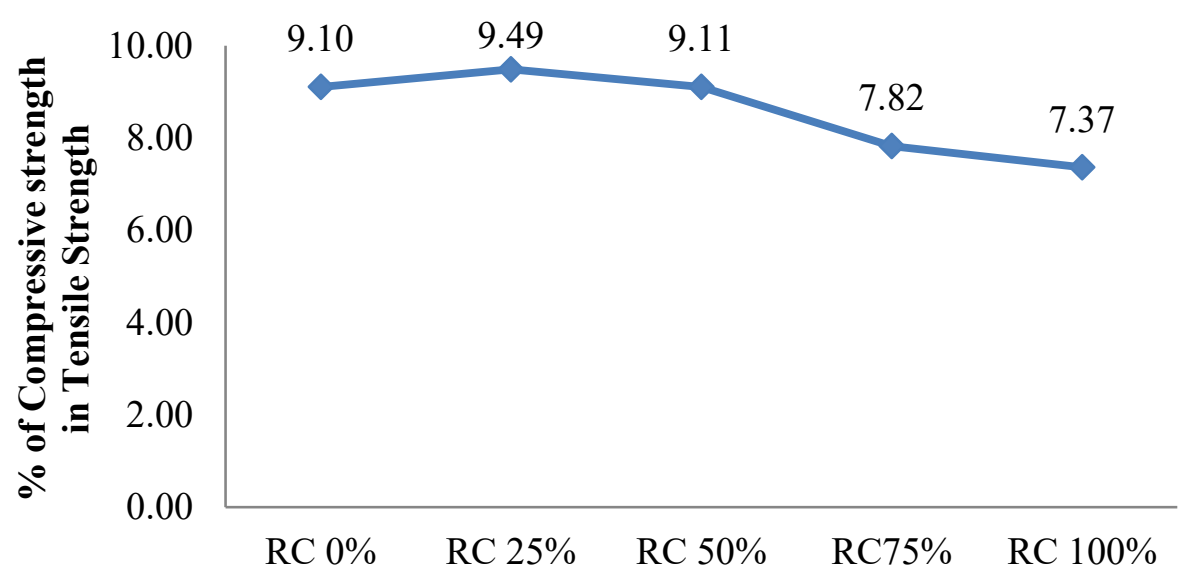

Figure 3. The relation between Percentage of Split Tensile Strength to Compressive Strength 


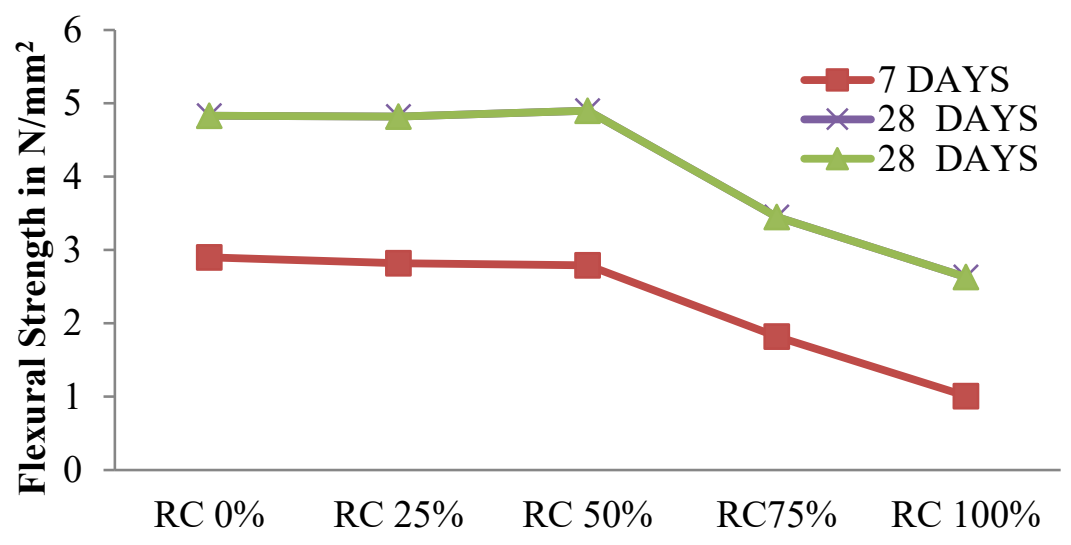

Figure 4.Flexural strength

\section{Flexural Strength}

A universal testing machine with a stacking limit of $1000 \mathrm{kN}$ was utilized to evaluate the flexural qualities of concrete. As shown by the ASTM, the stacking was applied at a rate that expanded the most extreme pressure gave an account of the strained surface between $0.9 \mathrm{MPa}$ each moment. At the ages of 7, and 28 days, the flexural strength is estimated. When contrasted with other blend extents of the percentage of silica fume, $0 \%$ replacement of reused aggregate was the cutoff. This distinction can be because of a diminishing in the consistency of the hard and fast mortar interfacial exchange zone as the extent of reused aggregate in the example increments, bringing about a lower mechanical strength under turning conditions.

\section{Rapid Chloride Permeability Test}

According to ASTM C1202, a $50 \mathrm{~mm}$ thick, $100 \mathrm{~mm}$ thick gauge solid model is exposed to a DC voltage of $60 \mathrm{~V}$ for 6 hours as part of an ASTM C1202 evaluation. As demonstrated in figure 5, one compartment had a 3.0 percent $\mathrm{NaCl}$ course of action and the other had a $0.3 \mathrm{M} \mathrm{NaOH}$ strategy. The aftereffects of this test have appeared in Table 4. The chloride goes through the solid example in this investigation, which was required following 28 days of restoring, demonstrating the penetrability of the solid. The charge transferred by coloumbs values is derived from the hardware screen, and these characteristics are compared to the ASTM C1202 standard characteristics.

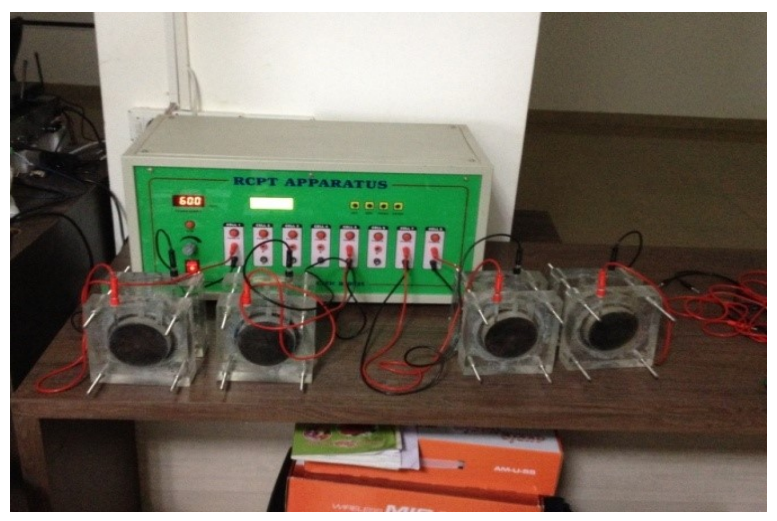

Figure 5. Rapid Chloride Permeability Test 


\section{Sorptivity Test}

The hair like rising level of consistency on generally homogeneous material can be utilized to dispense with sorptivity. The test liquid was comprised of water. After throwing, the chambers were lowered in water for 28 days to direct. Following drying in a holder at a temperature of $100+$ $10{ }^{\circ} \mathrm{C}$, the model was gagged with a water level close to $5 \mathrm{~mm}$ over the surface. As shown in the test result table 5, this demonstrates that reused coarse aggregate has infinitely better pore structures, vehicles, and transcendent volumes than the normal coarse aggregate.

Table 4. Rapid Chloride Permeability Test

\section{S.No Mix Id Charge Pass In Coloumbs (C) As Per ASTM}

\begin{tabular}{cccc}
\hline 1 & $\mathrm{RC} \mathrm{0 \%}$ & 2605 & Moderate \\
2 & $\mathrm{RC} 25 \%$ & 2414 & Moderate \\
3 & $\mathrm{RC} 50 \%$ & 2245 & Moderate \\
4 & $\mathrm{RC} 75 \%$ & 2010 & Moderate \\
5 & $\mathrm{RC} 100 \%$ & 1715 & LOW \\
\hline
\end{tabular}

Table 5. Sorptivity Test

\begin{tabular}{cccc}
\hline S.No & Mix Id & Sorptivity $\mathbf{x} \mathbf{1 0}^{-\mathbf{6}} \mathbf{~ m m} / \mathbf{m i n}$ & Rate of Absorption I mm \\
\hline 1 & RC 0\% & 4.50 & 101.62 \\
2 & RC25\% & 5.36 & 111.23 \\
3 & RC50\% & 6.28 & 125.60 \\
4 & RC75\% & 6.72 & 131.49 \\
5 & RC100\% & 7.36 & 143.56 \\
\hline
\end{tabular}

\section{Conclusion}

The research paper contributed to the current SCC literature by examining the effects of different levels of RCA integration on workability, strength, and, most importantly, durability.

- According to the workability checks, the viscosity of the SCCs increased as the RCA material was increased, as did sieve segregation resistance. When RCA usage exceeded $50 \%$, the SCC's passing capacity was found to be substantially reduced; however, the 75 percent RCA and 100 percent RCA SCCs were still within reasonable passing ability limits.

- However, with the aid of silica fume and fly ash, it was possible to manufacture good quality $\mathrm{RAC}$ that met the concrete strength requirements. 
- The coulomb reduction identified in the chloride diffusion test for the fly ash and silica fume concretes was related to micro structural changes and might even be due to the decline in pore solution conductivity.

- The safety from chloride molecule passageway deteriorated as the reused concrete material grew longer. In either case, the opposition was strengthened by mixing silica fume residues in concrete mixers. However, these properties are inferior to those of ordinary aggregate concrete with the same volume and variety of recycled concrete

\section{References}

[1] Sherif A. Khafaga (2014) "Production of High strength self compacting concrete using recycled concrete as fine and /or coarse aggregates". World applied sciences journal 29940 : 465-474.

[2] Ozbakkaloglu, T.; Gholampour, A.; Xie, T.Y. "Mechanical and durability properties of recycled aggregate concrete: Effect of recycled aggregate size and content on the behaviour". J. Mater. Civ. Eng. vol. 30, pp. 04017275, 2017. https://doi.org/10.1061/(ASCE)MT.1943-5533.0002142

[3] B. Gonza' lez-Fonteboa , F. Martı'nez-Abella, "Concretes with aggregates from demolition waste and silica fume Materials and mechanical properties," Building and Environment, vol 43, pp. 429-437, 2008. https://doi.org/10.1016/j.buildenv.2007.01.008

[4] Isaia, G. C., Gastaldini, A. L. G., and Moraes, R."Physical and pozzolanic action of mineral additions on the mechanical strength of high-performance concrete." Cem. Concr. Vol. 25, pp. 6976, 2003. https://doi.org/10.1016/S0958-9465(01)00057-9

[5] Kamal M.M, Safan M.A.,Etman Z.A and Eldaboly E.A(2013).'Evaluating the prolonged properties of fresh self compacting concrete incorporating recycled aggregates.'International journal of current engineering and technology ISSN 2277-4106. Vol :3 issue :2. https://doi.org/10.21608/erjm.2013.67433

[6] Nwzad Abduljabar Abdulla1," Effect of Recycled Coarse Aggregate Type on Concrete". J. Mater. Civ. Eng. vol. 27(10), pp. 04014273, 2015. https://doi.org/10.1061/(ASCE)MT.1943-5533.0001247

[7] Moslem Mohammadi Jatani, Ali delnavaz(2017)." A study on strength and durability of self compacting concretes made of recycled aggregates. "Journal of structural engineering and Geotechnics

[8] P. Saravana Kumar and G. Dhinakaran, "Effect of Admixed Recycled Aggregate Concrete on Properties of Fresh and Hardened Concrete", Journal of Materials in Civil Engineering, vol. 24, pp. 494-498, 2012. https://doi.org/10.1061/(ASCE)MT.1943-5533.0000393

[9] Premkumar R, Ramesh BabuChokkalingam and M Shanmugasundaram, "Durability Performance of Fly Ash and Steatite Powder Based Geopolymer Concrete", IOP Conference Series: Materials Science and Engineering, vol. 561, 012055, 2019, Available from: https://doi.org/10.1088/1757-899X/561/1/012055 